\title{
O ecossistema empreendedor, o direito aplicável as startups no Brasil e a atuação do
}

\section{Advogado}

The entrepreneurial ecosystem, the law applicable to startups in Brazil and the role of the Lawyer

El ecosistema emprendedor, la ley aplicable a las startups en Brasil y el rol del Abogado

Recebido: 07/05/2021 | Revisado: 13/05/2021 | Aceito: 16/05/2021 | Publicado: 04/06/2021

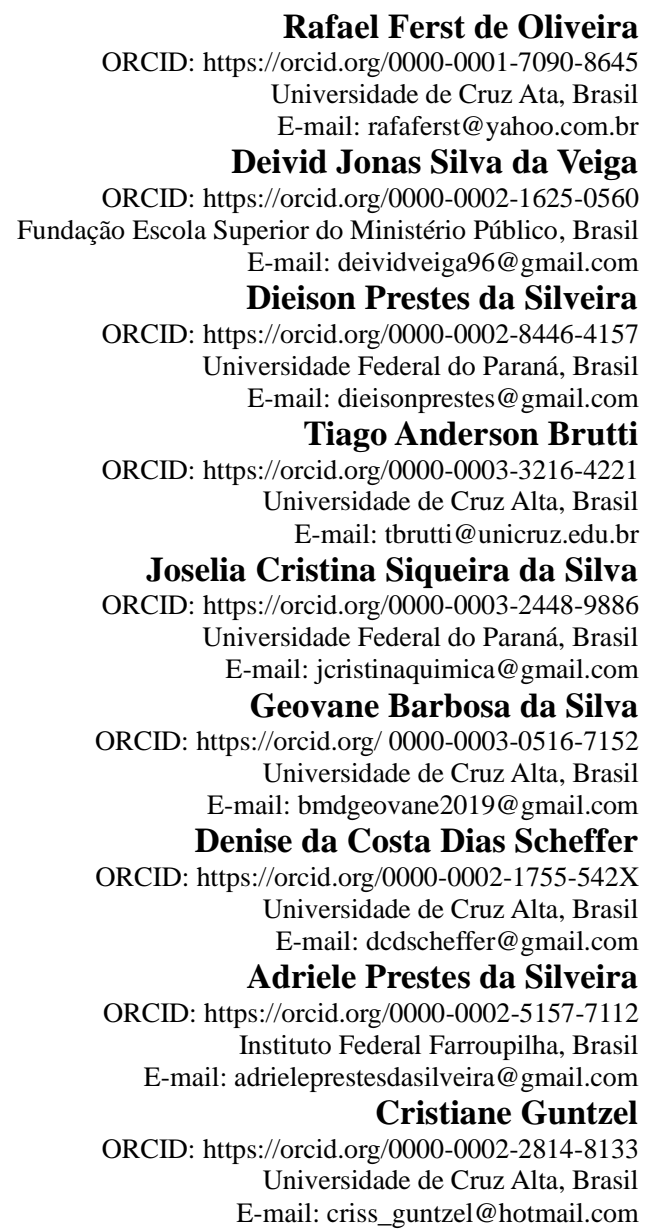

\section{Resumo}

Este artigo tem o objetivo de compreender as prováveis implicações das aceleradoras de startups na economia brasileira e suas nuances jurídicas no Direito brasileiro, mensurando o impacto de sua atividade e as formas pelas quais elas atuam. A abordagem metodológica que estrutura esta pesquisa é a qualitativa, de cunho bibliográfico, com abordagem do tipo hipótética dedutiva, cujo o exame dos dados ocorreu por meio da Análise Textual Discursiva, abrangendo consultas a informações públicas disponíveis sobre os programas brasileiros que assessoram as organizações em análise. O roteiro da investigação inicia-se com o estudo conceitual do ecossistema empreendedor e das startups à luz do Direito Empresarial; prossegue-se com uma digressão a respeito das oportunidades que a inovação pode gerar, especialmente no âmbito dos pequenos negócios. Em seguida, busca-se compreender a participação do investidor anjo, e seus aspectos jurídicos. Por fim, são examinados os papeis do advogado frente aos principais desafios do direito em relação a expansão de startups no cenário nacional. Por meio deste estudo foi possível compreender o impacto da presença de aceleradoras de startups na economia, bem como as soluções jurídicas para o desenvolvimento consistente do ecossistema empreendedor brasileiro.

Palavras-chave: Investidor-anjo; Startups; Direito brasileiro; Inovação digital. 


\begin{abstract}
This article aims to understand the likely implications of startup accelerators in the Brazilian economy and their legal nuances in Brazilian law, measuring the impact of their activity and the ways in which they operate. The methodological approach that structures this research is a qualitative one, of bibliographic nature, with a deductive hypothetical approach, whose examination of the data took place through Discursive Textual Analysis, encompassing consultations on public information available on Brazilian programs that assist organizations in analyze. The research script begins with a conceptual study of the entrepreneurial ecosystem and startups in the light of Corporate Law; we continue with a digression about the opportunities that innovation can generate, especially in the scope of small businesses. Then, it seeks to understand the participation of the angel investor, and its legal aspects. Finally, the roles of the lawyer are examined in relation to the main challenges of the law in relation to the expansion of startups in the national scenario. Through this study it was possible to understand the impact of the presence of startup accelerators on the economy, as well as the legal solutions for the consistent development of the Brazilian entrepreneurial ecosystem.
\end{abstract}

Keywords: Angel investor; Startups; Brazilian law; Digital innovation.

\title{
Resumen
}

Este artículo tiene como objetivo comprender las posibles implicaciones de los aceleradores de startups en la economía brasileña y sus matices legales en la legislación brasileña, midiendo el impacto de su actividad y las formas en que operan. El enfoque metodológico que estructura esta investigación es un enfoque cualitativo, bibliográfico, con un enfoque hipotético deductivo, cuyo examen de los datos se realizó a través del Análisis Textual Discursivo, abarcando consultas sobre la información pública disponible sobre los programas brasileños que ayudan a las organizaciones en el análisis. El guión de la investigación comienza con un estudio conceptual del ecosistema emprendedor y startups a la luz del Derecho Corporativo; Seguimos con una digresión sobre las oportunidades que puede generar la innovación, especialmente en el ámbito de las pequeñas empresas. Luego, busca comprender la participación del ángel inversionista y sus aspectos legales. Finalmente, se examinan los roles del abogado en relación a los principales desafíos de la ley en relación a la expansión de las startups en el escenario nacional. A través de este estudio fue posible comprender el impacto de la presencia de aceleradores de startups en la economía, así como las soluciones legales para el desarrollo consistente del ecosistema emprendedor brasileño.

Palabras clave: Inversor-angeles; Inauguración; Ley brasileña; Innovación digital.

\section{Introdução}

O empreendedorismo é um fenômeno socioeconômico global que está em crescente evidência. Governos, universidades, empresas e indivíduos estão ávidos por compreender melhor este conceito, observando com atenção todo tipo de informação qualificada e independente que surja a seu respeito. O elo preciso que conecta este número crescente de oportunidades, à enorme capacidade de execução dos empreendedores é a inovação, que transforma realidades, expandindo nossa percepção sobre o mundo que nos rodeia. O empreendedor vive, assim, desafiando-se constantemente para construir novos empreendimentos ou renovar empreendimentos já existentes que geram impacto positivo na sociedade. É dentro deste processo que se pode definir a startup como uma empresa criada com o objetivo de gerar impacto social e/ou econômico, por meio de um processo inovador intenso, independentemente de seu tamanho ou desempenho de mercado (Rodriguez, 2015).

Em um aspecto geral, as startups são projetos de empresas com enorme potencial de crescimento, são fomentadoras de inovação. Essas corporações são contumazes em impactar o mercado oferecendo inovações tecnológicas com modelos de negócios muitas vezes alavancado para um público cada vez maior. Sua relevância social, está no fato de ser empresas geradoras de oportunidades, principalmente empregos, aquecendo a economia com modelos de negócios únicos e muitas vezes moldáveis a qualquer região.

Salienta-se que as startups se destacam por apresentar modelos de negócios que desafiam concepções padrões já existentes no mercado, os modelos apresentados por startups repensam e inovam solucionando aspectos e acelerando setores específicos do mercado corporativo, como produtos e serviços. O uso da tecnologia é intrínseco a concepção de startup, desta forma além de ser uma empresa com enorme potencial de crescimento e geradora de empregos, ela beneficia o próprio usuário que encontra nela uma solução tecnológica eficaz e ágil para eventuais problemas ou dificuldades no uso de produtos ou serviços. Justifica-se a pertinência no debate deste assunto no tocante as questões emergentes e que apresentam reflexos na 
sociedade, como por exemplo, aspectos econômicos, sociais, culturais, ambientais, políticos, hegemônicos e que circundam as startups.

Em vista disso, deve-se haver discussões acerca desta temática no âmbito da pesquisa, uma vez que as Startups são fomentadoras de oportunidades no mercado corporativo, carecendo de uma atenção especial quanto aos aspectos jurídicos que o cercam. Penando nisso, o objetivo geral desta pesquisa é compreender as prováveis implicações das aceleradoras de startups na economia brasileira e suas nuances jurídicas no Direito brasileiro, mensurando o impacto de sua atividade e as formas pelas quais elas atuam. Para atingir o objetivo da pesquisa, será abordado os investimentos-anjo e seus aspectos jurídicos no sentido de compreender o ecossistema empreendedor na geração de oportunidades por meio da inovação. Além do mais, será abordada a atuação dos advogados frente aos principais desafios do direito em relação a expansão de startups no cenário nacional.

\section{Metodologia}

O tipo de pesquisa realizada baseou-se em uma pesquisa qualitativa, de cunho bibliográfica, em razão da estruturação em que os pontos estudados remeteram a análise. Por outro lado, também se utilizou artigos científicos, revistas e demais materiais em que a temática foi contemplada. Pode-se dizer que as pesquisas realizadas sob o enfoque qualitativo utilizam meios de interpretação subjetivos com foco na compreensão histórica de vertentes como valores em sociedade, crenças, e ações diretamente atreladas ao agir dos sujeitos perante a coletividade (Minayo, 1983).

Ressalta-se que para a análise dos dados investigados, foi empregado como meio de compreensão a Análise Textual Discursiva. Conforme Moraes e Galiazzi (2006, p. 117), a referida análise pode ser descrita como:

[...] um processo que se inicia com uma unitarização em que os textos são separados em unidades de significado. Estas unidades por si mesmas podem gerar outros conjuntos de unidades oriundas da interlocução empírica, da interlocução teórica e das interpretações feitas pelo pesquisador. Neste movimento de interpretação do significado atribuído pelo autor exercita-se a apropriação das palavras de outras vozes para compreender melhor o texto. Depois da realização desta unitarização, que precisa ser feita com intensidade e profundidade, passa-se a fazer a articulação de significados semelhantes em um processo denominado de categorização. Neste processo reúnem-se as unidades de significado semelhantes, podendo gerar vários níveis de categorias de análise. A análise textual discursiva tem no exercício da escrita seu fundamento enquanto ferramenta mediadora na produção de significados e por isso, em processos recursivos, a análise se desloca do empírico para a abstração teórica, que só pode ser alcançada se o pesquisador fizer um movimento intenso de interpretação e produção de argumentos. Este processo todo gera metatextos analíticos que irão compor os textos interpretativos.

Assim, resta claro a relevância da dita espécie de análise de dados na construção do presente estudo. Além do mais, fez-se a aplicação do método hipotético-dedutivo, que segundo Popper (1975), é um método que almeja uma solução, mediante tentativas, sejam elas por meio de teorias ou hipóteses, além da eliminação de possíveis erros que podem ocorrer durante a pesquisa. O referido método também é conhecido como "método de tentativas e eliminação de erros". Salienta-se que o referido método foi aplicado com uma abordagem descritiva, no intuito de descrever acerca dos conceitos e desafios que tanto as aceleradoras de startups identificadas no país, bem como os advogados de um modo geral terão de lidar com as novas nuances do mercado nacional e global.

\section{Resultados e Discussão}

\subsection{O Ecossistema Empreendedor}

Empresas novas e com alto potencial em desenvolvimento, as startups, têm ganhado grande significância no mercado financeiro, principalmente no que diz respeito a negócios que demandam investimentos, denominados anjos. Não se pode duvidar que a atividade empresarial alavanca a economia dos países capitalistas e promovem desenvolvimento do mercado 
financeiro. O ecossistema empreendedor é composto por um conjunto de atores empresariais e governamentais que interligam organizações empresariais (empresas, capital de risco, investidores-anjos) e bancos, instituições (universidades, órgãos do setor público, organismos financeiros). Da mesma forma, se juntam para se conectar, mediar e gerir o desempenho dentro do ambiente empresarial local (Mason, 2014).

As aceleradoras ajudam os empreendedores a construir e definir os seus produtos iniciais, além de identificar segmentos de clientes e, por fim, obter recursos necessários. De forma analítica, elas buscam desenvolver programas com uma aceleração de mais ou menos três meses de duração, ajudando as startups com o processo do novo empreendimento, fornecendo uma pequena quantia em capital, espaço para trabalhar, oportunidades de networking e mentoria com técnicos da área, investidores-anjo, empresários, capital de risco, entre outros. Finalmente, a maioria dos programas termina com um grande evento, onde será realizada a apresentação final do empreendimento para o público de possíveis investidores (Cohen, 2013).

Cabe destacar que esta prática se tornou mais forte no Brasil na última década, quando até mesmo o Governo decidiu incentivar e angariar com a criação de incubadoras e negócios tecnológicos como forma de expandir o desenvolvimento da ciência e inovação do país. Um bom exemplo de ecossistema é a região sul do Brasil, que é um dos principais núcleos de tecnologia e inovação, e, de acordo com a Associação Brasileira de Startups - ABStartups ${ }^{1}$, o estado do Rio Grande do Sul concentra 964 startups, sendo 596 delas somente em sua capital. O ecossistema gaúcho se inspira no desenvolvimento econômico de cidades como Barcelona, na Espanha, e Medellín, na Colômbia, para, através da inovação, tornar o estado não apenas referência nacional em revolução urbana, mas também mundial (ABStartups, 2020).

O relatório global Startup Ecosystem Report ${ }^{2}$, da startup Genome, indica a capital paulista como um dos ecossistemas mais promissores do mundo. O estudo aponta a cidade como o maior centro financeiro do Brasil, com potencial de gerar até US\$ 24 bilhões nos próximos dez anos. Segundo a Associação Brasileira de Startups $^{3}$ (Abstartups) são mais de 2.600 empresas iniciantes na terra da garoa e também estão datados mais de 400 espaços de inovação. Nesta décima parte do especial de Whow! (Uau), sobre os hubs de inovação pelos estados brasileiros, vamos mostrar os principais destaques na maior metrópole do País. O maior estado brasileiro também é grande no sucesso de seus empreendimentos. Dentre os 11 unicórnios brasileiros, oito são nativos do Estado: Nubank, 99, Gympass, Movile (iFood), Loggi, QuintoAndar, Wildlife Studios e Loft. Além disso, o relatório informa que o município é terra fértil para negócios de ciências da vida e é o lar de universidades de alta qualidade. Mas o tamanho da comunidade não se restringe à capital: as regiões de Sorocaba, Campinas, Barretos e de todo o ABC Paulista também começam a desenvolver um agrupamento forte e estruturado (ABStartups, 2020).

As Startups necessitam de cuidados jurídicos e profissionais especializados que busquem garantir a blindagem jurídica e melhores oportunidades às novas negociações, para que o negócio não tenha mais um risco e desencadeie sérias consequências. Advogados conseguem trabalhar melhor e, arbitragem privadas estão nascendo e desafogando o sistema judiciário, há tantos anos travado. Há um enorme campo de melhorias que vão surgir nos próximos anos. Novas tecnologias estão fazendo a justiça mais eficiente e rápida. E com essas melhorias, é natural ver o assunto ganhando mais espaço na mídia. Por isso, as startups jurídicas é que estão mudando o direito no país, como veremos a seguir (Startse, 2018).

Como a Finch Soluções, que nasceu dentro de um dos maiores escritórios de advocacia do país, o JBM \& Mandaliti, que precisava agilizar e baratear os processos de contencioso de massa - ou seja, um ganho enorme de produtividade em ações

\footnotetext{
${ }^{1}$ A “Associação Brasileira de Startups", doravante denominada "Associação", é uma pessoa jurídica de direito privado, constituída sob a forma de associação civil, sem fins lucrativos e regidas por um estatuto social e pelas disposições legais aplicáveis.

${ }^{2}$ O Relatório Global do Ecossistema de Inicialização 2019, fornece informações e orientações para líderes públicos e privados em dezenas de países e cidades sobre como cultivar ecossistemas de inicialização vibrantes.

${ }_{3}^{3}$ É uma instituição sem fins lucrativos que visa impulsionar o cenário de empreendedorismo tecnológico no Brasil e auxiliar novos profissionais no ramo.
} 
coletivas. Embora a trajetória não tenha sido uma trajetória típica de startup, a empresa foi separada em 2013 e já conta com 620 funcionários. Desde 2015 ela usa o Watson da $\mathrm{IBM}^{4}$ e oferta programas de gestão jurídica, análise de dados, pesquisa avançada de jurisprudência (quando um caso parecido já foi julgado anteriormente), acompanhamento de processos e automação de agendamentos (o que pode reduzir de meses para segundos o tempo de alguns processos). O selling point da companhia é simples: ao aumentar a produtividade dos advogados, a Finch Soluções diminui custos com folha de pagamento de escritórios e departamentos jurídicos (Startse, 2018).

A JusBrasil, tem diversos processos jurídicos públicos que podem ser acessados pela população. Além disso, ela busca facilitar o acesso à justiça através de informação gratuita sobre direitos e deveres, e da busca por advogados, para que todos possam ter seus direitos exercidos na prática. Ela foi fundada em 2008 e é uma das principais startups brasileiras. Sua estratégia de monetização é oferecer serviços pagos, como um alerta que envia notificações sobre processos a partir de Keywords (palavras-chave), CPF ou CNPJ, busca por citações em peças jurídicas similares, entre outras ferramentas.

A Jusbrasil é uma empresa de tecnologia, onde engenheiros somam esforços com pessoas com background ${ }^{5}$ jurídico para resolver velhos problemas com novas abordagens. Então, mesmo tendo alguns bacharéis da nobre área, a maioria do time é composta por desenvolvedores de software, designers e afins. O seu ambiente é descontraído (inspirado em empresas como Google), o código de vestimenta é relaxado e os relógios de ponto abolidos, dando lugar à flexibilidade de horários. A Looplex é uma plataforma para automação inteligente de documentos, como petições e contratos, a ideia da Looplex é oferecer modelos inteligentes e customizáveis de documentos jurídicos, o que reduz (e muito) o tempo de criação deles. É uma das mais revolucionárias empresas de legal tech do país. A sua equipe de advogados, engenheiros e matemáticos criou a primeira plataforma de inteligência artificial para automação de conteúdo e geração de conhecimento na área jurídica, e com isso nasceram os primeiros Engenheiros Jurídicos. Dois exemplos: uma contestação de caso bancário demoraria 3 horas para ser feita por um advogado, com a solução da Looplex demora só 20 minutos. Já uma debênture demoraria 20 horas, mas dura apenas 30 minutos com a solução (Startse, 2018).

Com isto a Justto Inovações Tecnológicas para Resoluções de Conflitos Online, que foi acelerada pela $\mathrm{ACE}^{6}$, é uma plataforma de arbitragem (através da Arbitranet ${ }^{7}$ ) e conciliação judicial (com a Acordo Fácil), onde você acompanha o seu caso em tempo real, sem precisar sair de casa. Todas as informações ficam registradas e podem ser acessadas quando você quiser. A empresa, após receber a sua reclamação, irá cadastrar o conflito na plataforma da JUSTTO, com o objetivo de tornar a comunicação e o registro de informações mais eficiente. Uma vez que o conflito está no nosso sistema, nós vamos entrar em contato com você e todas as partes envolvidas, através de e-mail e WhatsApp®, com o objetivo de facilitar o seu contato com a empresa e, em todas as mensagens que você irá receber, haverá um link de cadastro, que permitirá que você acompanhe o seu caso pelo celular ou computador (Startse, 2018).

$\mathrm{O}$ andamento da sua negociação poderá ser acompanhado pela internet, bem como enviar uma contraproposta e conversar através de um chat com os representantes da empresa. Após o acordo, você poderá acompanhar o andamento do seu caso. A arbitragem é importante para resolver problemas entre duas partes, parecido com a conciliação (que já resolveu mais de 5.000 casos fora da justiça). E o simples ato de tirar os processos do sistema judiciário é interessante para agilizar o processo e baixar custos dos processos. A plataforma Advys, de assistência jurídica, permite que se tire dúvidas jurídicas de diversas maneiras pela internet, voltada para pessoas físicas e pequenas empresas, é uma empresa que busca democratizar a

\footnotetext{
${ }^{4}$ Watson é a plataforma de serviços cognitivos da IBM para negócios. A cognição consiste no processo que a mente humana utiliza para adquirir conhecimento a partir de informações recebidas.

${ }^{5}$ É uma palavra em inglês que pode ter vários significados, entre eles experiência, fundo, antecedentes, plano de fundo, contexto, ambiente, circunstâncias, meio, educação, etc.

${ }^{6}$ A aceleradora ACE, com sede em São Paulo - SP, trabalha levando startups a patamares globais e entrega projetos de inovação com resultados em grandes corporações.

${ }^{7}$ É um app onde pessoas e empresas iniciam seus casos e um especialista decide o caso de forma a substituir completamente o Judiciário.
} 
informação, oferecendo consultoria nas áreas empresarial, contábil, forense, financeira e societária. Com um serviço permanente de resposta às dúvidas do dia-a-dia, espera minimizar a frustração pessoal motivada por gastos desnecessários de tempo e dinheiro decorrentes de apostas equivocadas, estratégias ineficientes de negócios, erros de administração, contratos mal negociados, decisões trabalhistas questionáveis, incapacidade de negociação de dívidas, entre outras dificuldades (Startse, 2018).

O Legal One ${ }^{\mathrm{TM}}$ é o software jurídico que nasceu dentro da Thomson Reuters ${ }^{8}$, uma das maiores empresas de comunicação do mundo. Essa plataforma reúne processos, conteúdo legal, financeiro, contratos, clientes e contatos. A ideia é integrar departamentos jurídicos e escritórios para aumentar a eficiência entre os dois e, em favor da otimização das operações do Direito. Apresenta-se como um sistema jurídico único, que utiliza a expertise de soluções consagradas no mercado e, unindo tecnologia inteligente, evolução rápida e conteúdo jurídico de excelência em um único programa, com a credibilidade do selo editorial da Revista dos Tribunais ${ }^{9}$. Dessa forma, o mercado empreendedor pode agir demandando mudanças legais e ocasionalmente, boas práticas privadas, uma vez que na ausência de institutos jurídicos aplicáveis ao caso concreto, o empreendedor busca formas alternativas e inovadoras para resolver seus conflitos e problemas. Azevedo (2016), considera que a flexibilidade significa capacidade de adaptar-se a novos modelos de negócio. Em outras palavras, é possível dizer que, para atender às necessidades de startups, os instrumentos jurídicos dos países devem ser tão dinâmicos quanto elas.

\subsection{A inovação gerando oportunidade}

Além do fato de as startups operarem em ambientes de notória incerteza, em muitas hipóteses tais empresas podem ser consideradas "opacas" em termos de informações. Isso significa que elas inicialmente recorrerão a um financiamento interno inicial e, ao longo de sua vida, poderão buscar alternativas de financiamento externo que dependerão de seu grau de assimetria informacional, escala, necessidade de investimento e estruturação de seus ativos. Como startups são inovadoras em seus serviços/produtos, geralmente, seus produtos podem ser classificados como estando no quadrante do ponto de interrogação, provavelmente vindo a tornar-se cash cows ou cachorros posteriormente, de acordo com seu desempenho. Por fim uma estrela (um produto com alto Market share e crescimento constante) tende a tornar-se uma cash cow com o decorrer do tempo, caso consiga manter sua liderança de mercado. Por conta disso, o eixo horizontal (que representa o mercado) tem menos importância na atualidade, devendo ser substituído pela capacidade de uma empresa se adaptar a inovação (Reese; Moose; Venema, 2014). A Figura 1 mostra a Matriz de Crescimento e Fatia de Mercado - Matriz BCG.

\footnotetext{
${ }^{8}$ Livraria Jurídica Online.

${ }^{9}$ A Revista dos Tribunais Online® é uma plataforma online de pesquisa jurídica que pode ser acessada de qualquer local.
} 
Figura 1: Matriz BCG.

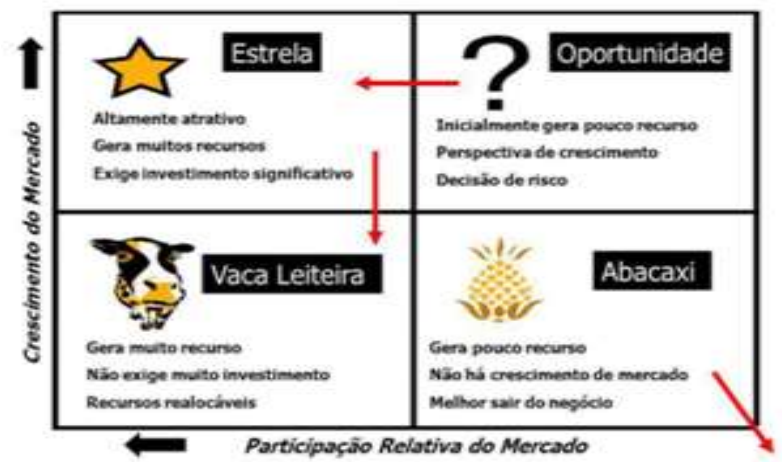

Fonte: Boston Consulting Groug (2018).

Na prática, a maioria dos investimentos externos típicos de startups se operam por meio de instrumentos híbridos, que misturam direitos típicos de equity com alguns de debt - como os contratos conversíveis, por exemplo. Veremos mais adiante que os mecanismos de investimento-anjo no Brasil consistem basicamente em compras (principalmente futuras) de participações em empresas investidas. Além disso, parcela considerável da indústria de Private Equity (capital próprio) e Venture Capital (capital de risco) brasileira opera por meio de Fundos de Investimentos em Participações (FIPs), fundos que basicamente tem a obrigação de adquirir títulos e valores mobiliários conversíveis ou permutáveis em ações ou quotas de emissão de empresas, devendo ainda participar do processo decisório da sociedade investida, com efetiva influencia na definição de sua política estratégica e na sua gestão (Brasil, 2016).

Contudo, o grande problema no financiamento de startups é justamente a incapacidade de garantir ou ao menos estimular um retorno para o investidor. Tanto no modelo de debt (débito) como no de equity (capital), investidores injetam capital em um negócio estimando um retorno futuro: no primeiro caso, em forma de pagamento de dívida; no segundo, em forma de um lucro obtido por meio do valor crescente que uma empresa vai adquirindo através do tempo, se prosperar.

Por que razão, a utilização de instrumentos conversíveis se justifica: investidores com conhecimento de startups sabem que a maior chance de obterem um retorno não é cobrando o valor da dívida no futuro, e sim convertendo-a em participação e ganhando capital com algum procedimento de desinvestimento. Nesse cenário, é importante ter em mente que $25 \%$ das startups brasileiras "morrem" em menos de um ano ${ }^{10}$. Além do mercado em que opera, a própria estrutura da startup pode acabar por afastar investidores. Questões como assimetria informacional (quando há uma relação entre dois ou mais agentes e nem todas as partes possuem informações privilegiadas em detrimento de outras envolvidas nessa relação de equilíbrio) e problemas de agencia (conflitos entre principais e agentes na delegação de competências decisórias e relações comerciais) são questões importantes que incrementam o caráter de incerteza da startup e afastam investidores potenciais (Agência IN, 2014).

A relação do Direito com os processos de investimentos em startups é responsável pela gestação e propagação de inúmeras consequências no campo pratico, que tem forçado advogados e operadores do Direito a criar e adaptar mecanismos para operacionalizar os aportes de capital em empresas nascentes inovadoras.

O financiamento externo de uma startup é fundamental para seu desenvolvimento, sendo uma de suas principais características. Isso porque o capital humano - aquele representado pelo conhecimento agregado pelos indivíduos envolvidos em um negócio - cumpre papel significativo no desempenho da startup, principalmente quando tal capital possui formação especifica (Seghers; Manigart; Vanacker, 2012, p. 63).

\footnotetext{
${ }^{10}$ A Fundação Dom Cabral conduziu, no ano de 2014, uma pesquisa sobre a mortalidade de startups no Brasil. O relatório final da pesquisa encontra-se consolidado e pode ser acessado em www.fdc.com.br/blogespacodialogo/Documents/2014/causas_mortalidade_start ups_brasileiras.pdf.
} 
Outro ponto importante a ser destacado é o fato de investimento em startups acontecer em rounds (rodadas). Essa estratégia faz parte de um contexto conhecido como staging (encenação) de capital, típico de venture capitals (capital de risco) mas utilizado de forma bastante ampla no ciclo de vida de uma startup. Nesse sentido os investimentos são periodizados, o que permite aos investidores um monitoramento do uso do capital e do desempenho da startup entre cada período de investimento. Além disso, varia em montante investido. Ou seja, conforme uma empresa cresce, mais dinheiro ela irá receber. O gráfico a seguir, da Figura 2, demonstra os estágios de investimento em uma startup, inspirado no gráfico proposto por Cumming e Johan (2009):

Figura 2: Estágio de investimento em startups

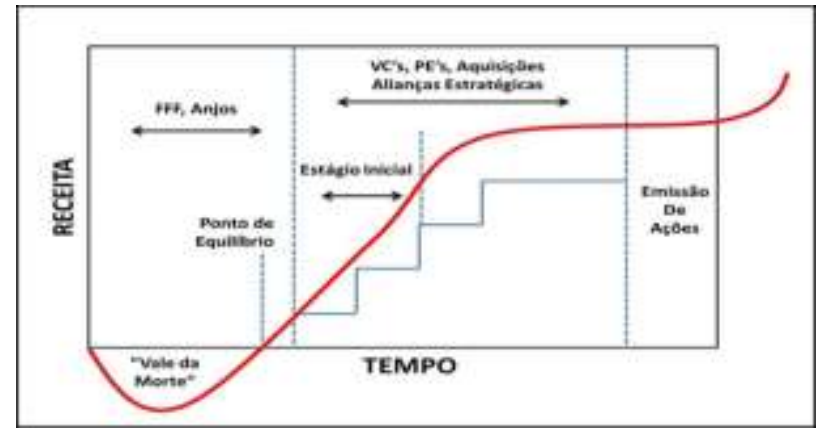

Fonte: Galvão (2018).

O gráfico é uma demonstração genérica das formas usuais de financiamento de uma startup ao longo de seu desenvolvimento, relacionando estágios com o lucro obtido pela empresa. Note que geralmente uma startup opera com déficit durante quase todo o processo de financiamento inicial, até o momento em que atinge o ponto de equilíbrio, quando começa a auferir lucro e chamar a atenção de fundos mais estruturados (venture capitals e private equity) que farão aportes em formato de rounds de investimento.

Inspirado no diagrama acima e tendo em mente a explicação relativa às séries de investimentos. Spina (2015) criou outra maneira de representação das rodadas de investimento com base na evolução das séries. Em seu gráfico, a quantidade de capital e a complexidade do investimento cresce acompanhando o volume de vendas de uma empresa. De acordo com o autor, uma startup inicialmente costuma receber investimentos da família, dos próprios fundadores e de amigos (FFeAs), podendo culminar na obtenção de "saída" por meio de bolsa de valores ao realizar IPO (Initial Public Offering). Graficamente, a chamada "Escada do Crescimento" é assim disposta na Figura 3.

Figura 3: Escada de Crescimento.

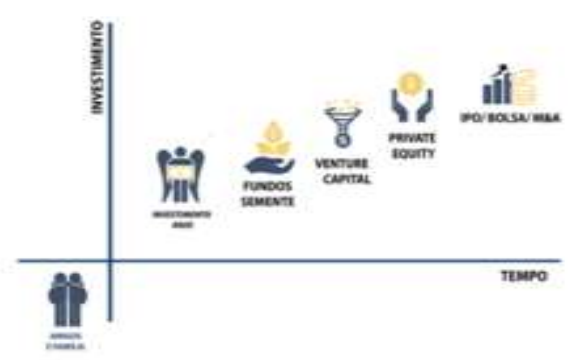

Fonte: Anjos do Brasil (2015). 
Logo após este estágio, surge a primeira figura de investimento externo que estabelecerá uma relação mais profunda com o empreendedor: o investidor-anjo. Esse agente efetua investimentos de "valor agregado", pois o investidor-anjo atua não somente realizando aportes de capital, mas também aconselha o empreendedor e utiliza-se de sua experiência e relacionamentos pessoais networking (trabalho em rede) para ajudar a startup a se desenvolver visando, é claro, maiores retornos. Esse tipo de investidor que traz consigo benefícios que vão além do valor financeiro costuma ser denominado Smart Money (dinheiro inteligente). Nessa modalidade, os investimentos são ligeiramente maiores do que aqueles realizados pelos (FFeAs), principalmente quando os investidores-anjo se organizam em grupos para realizar um investimento, ao que se denomina "sindicato".

\subsection{As Startups, o advogado e a desconsideração da personalidade jurídica}

O principal desafio do Direito em relação as startups não é em assuntos específicos, mas em como trabalhar com os novos padrões de inovação tão dinâmicos, em um País em que há uma forte cultura legalista, uma vez que no Brasil a lei é a principal fonte do Direito. Sabe-se que a legislação não consegue se movimentar num ritmo que o mercado exige, além disso, o próprio empreendedor possui um perfil mais dinâmico do que os ambientes burocráticos brasileiros, quando se trata de obrigações comerciais legais. E, conforme exposto, o empreendedor encontra-se num "limbo de incerteza jurídica" e, muitas vezes, não confia em advogados, por considerar que estes "não entendem suas necessidades" (Nybo, 2016).

Os profissionais legais (advogados), que devidamente capacitados agregam valor a startup, que por essência, são estruturas, constantemente, expostas ao risco. A atuação despreparada, pode minar o sonho e os investimentos do empreendedor e principalmente lhe trazer grandes prejuízos quanto a novos empreendimentos futuros. $\mathrm{O}$ ideal é que uma startup tenha assessoria jurídica desde o seu início. Assim, é essencial estabelecer um acordo societário entre os fundadores, que determine a participação efetiva de cada um, por meio de responsabilidade e estratégia para evitar casos de desligamentos. Além disto, é preciso proteger sua propriedade intelectual, com o registro da marca e a patente de tecnologias. Se for receber um investimento de terceiros, precisará de uma assessoria para revisão dos contratos e acordos com os investidores (Zuini, 2013).

Entretanto, as startups podem com auxilio profissional não somente externamente como internamente, com o profissional que se envolve na realidade daquela empresa e que possa gestar soluções jurídicas adequadas ao negócio. É possível antever que as startups muitas vezes identificam os problemas legais que as cercam, mesmo sem estas não possuírem uma consultoria voltada a esta questão, mas ainda assim existe a compreensão da importância da assistência por parte de um profissional que compreenda a realidade de uma empresa inovadora, pois o Direito nesse ponto funciona como uma proteção jurídica de qualidade, interna ou externa, auxilia na estruturação e solidez empresarial (Ibrahim, 2012).

A existência dos advogados é uma das características primordiais de ecossistemas de sucesso, sendo que, para essa tarefa deve ser capaz de compreender novas formas de expressão jurídicas, ou adaptar as tradicionais ao empreendedorismo moderno. O empreendedor deve procurar um assessor jurídico que tenha experiência de acordo com a sua necessidade. Pela falta de experiência na área especifica, ele pode não conhecer condições importantes que devem constar nos contratos ou tentar impor cláusulas fora dos padrões que podem até inviabilizar a transação. Evite utilizar um advogado amigo ou familiar que não tenha experiência em direito societário e em especial em transações de investimentos (Spina, 2012).

Observa-se que já existem escritórios de advocacia especializados em startups que muitas vezes aceitam permutar uma parte dos seus honorários por uma participação na empresa. Nesses casos, o percentual nunca deve ultrapassar $10 \%$. O Term Sheet, (memorando de entendimentos) é um documento, em geral não vinculante (ou seja, as partes podem não fechar o negócio ou até mesmo renegociar os termos), que costuma ser assinado pelas partes no momento inicial das negociações. Este documento traz as premissas básicas do investimento e servirá como um ponto de partida para a elaboração dos documentos 
definitivos da negociação.

É importante que as partes estejam cientes das expectativas que cada um tem em relação ao negócio. É aí que entra o Memorando de Entendimentos. Ele formaliza - de forma não vinculante - certos direitos e condições mínimas para ambas as partes, pontos que sejam vitais tanto para o investidor quanto para o empreendedor. Assim, evita-se que as partes possam eventualmente investir muito tempo em um processo de investimento para descobrir lá na frente que algumas premissas não estão alinhadas. Com base nisso foi elaborado os principais tópicos para o memorando, que costumam ser:

- Tipo de investimento a ser feito (se por dívida ou participação direta);

- As condições precedentes; Estrutura do negócio; Direitos do investidor, como preferência na liquidação, direito de preferência, governança na investida, entre outros;

- Confidencialidade e, principalmente a Exclusividade.

No universo empresarial, o memorando de entendimentos tem uma utilidade muito forte de alinhar bases negociais e expectativas das partes e servir como ponto de partida do projeto. Assim, as chances de sucesso do projeto tornam-se muito maiores. Incentiva-se, também, uma boa relação entre as partes. O memorando de entendimentos pode, ou não, obrigar as partes a concretizar o projeto. Desse modo, as partes ficam livres ou não para desistir dele. Independentemente disso, o memorando costuma estabelecer obrigações acessórias vinculantes. Por exemplo: como as partes dividirão os custos e despesas relacionados ao projeto e obrigações de confidencialidade e exclusividade.

No que diz respeito à desconsideração da personalidade jurídica, antes de mais nada, cabe salientar que esse instituto pode ser considerado um meio de coibir o uso indevido dos privilégios concedidos à pessoa jurídica e também uma forma de limitar, pode-se concluir que é uma maneira de fazer com que as pessoas se adequem aos deveres da personalidade para que seja usada apenas para o fim adequado. A teoria da desconsideração da personalidade jurídica começou a ganhar espaço no Brasil apenas por volta de 1960, com o professor Rubens Requião ${ }^{11}$. Em razão das inúmeras práticas de negócios fraudulentos, dos abusos cometidos por sócios que a jurisprudência se viu na necessidade de criar meios que ajudassem a identificar as fraudes e seus respectivos responsáveis para que o retirassem da proteção da pessoa jurídica e passassem a responder pelos abusos cometidos por si mesmo, como pessoa física, ou seja, é o desprezo do Poder Judiciário da personalidade independente da pessoa jurídica com a finalidade de que o sócio fraudulento responda com seu próprio patrimônio pelos abusos e fraudes cometidas, é a autorização para que o sócio se responsabilize civilmente por seus atos (Lopes, 2018).

Com o decorrer do tempo o código civil foi sofrendo alterações, mas a desconsideração da personalidade civil pouco se viu alterada desde a época de 70, quando proposto por João Moreira Alves ${ }^{12}$ no Anteprojeto do Código ofertado, de acordo com o novo Código Civil, a desconsideração da personalidade jurídica ficou desta forma:

Art. 50. Em caso de abuso da personalidade jurídica, caracterizado pelo desvio de finalidade, ou pela confusão patrimonial, pode o juiz decidir, a requerimento da parte, ou do Ministério Público quando lhe couber intervir no processo, que os efeitos de certas e determinadas relações de obrigações sejam estendidas aos bens particulares dos administradores ou sócios da pessoa jurídica.

A desconsideração é um meio que se equivale do direito de desencobrir o sigilo, o manto protetivo da personalidade jurídica autônoma da empresa, permitindo assim que o credo busque a satisfação de seu crédito juntamente às pessoas que

11 Jurista Comercialista, diplomou-se Bacharel em Direito, na Faculdade da Universidade do Paraná. A produção jurídica do professor Rubens Requião é extensa, chegando à publicação de mais de vinte estudos. Escreveu diversas monografias e passou a realizar conferências em diversas universidades do país. Em face de seus trabalhos jurídicos, veio a ser contemplado na qualidade de membro do Instituto de Direito Comparado da Faculdade de Direito de São Paulo. Também recebeu títulos de Sócio do Instituto dos Advogados da Bahia e do Paraná. Foi também o relator do anteprojeto de Lei que, posteriormente, se tornou a Lei que regulamenta o exercício da Representação Comercial (Lei $\mathrm{n}^{\circ}$ 4886/65).

${ }^{12}$ José Carlos Moreira Alves (Taubaté, 19 de abril de 1933), é um magistrado brasileiro. Foi ministro do Supremo Tribunal Federal (STF) de 1975 a 2003, tendo sido presidente daquela corte de 1985 a 1987. 
compõem a sociedade responsável pela empresa, ou seja, seus sócios e administradores. Portanto, só é permitido a quebra do sigilo quando verificado o abuso da pessoa jurídica, confusão patrimonial entre sócios ou sociedade, desvio de finalidade da empresa ou na hipótese de encerramento da empresa sem ser dada a devida baixa juntamente a junta comercial.

Dentro do ordenamento jurídico brasileiro, uma das maiores seguranças transmitidas a todo empreendedor que deseja abrir seu próprio negócio, ou ainda ingressar em um negócio já existente, é a chamada personalidade jurídica. A personalidade jurídica é justamente o que confere a separação patrimonial entre sócio, pessoa física, e empresa, pessoa jurídica, o que significa que as obrigações de um não podem atingir o patrimônio do outro.

É de extrema importância que o credor demonstre de forma clara e inequívoca que a personalidade jurídica agiu de maneira excessiva e abusiva de poderes, infringindo a lei ou o próprio contrato social, caracterizando-se assim como atos de malícia e prejuízos à empresa para que o patrimônio do sócio responda pelas dívidas da sociedade perante a aplicação da teoria da desconsideração da personalidade jurídica.

É necessário relatar que a desconsideração da personalidade jurídica se subdivide em outras duas teorias, sendo elas: a teoria maior da personalidade jurídica e a teoria menor da desconsideração da personalidade jurídica. A teoria menor da desconsideração da personalidade jurídica refere-se a toda hipótese de comprometimento do patrimônio do sócio por obrigação da entidade, reconhecendo assim o simples prejuízo do credor, assim possibilitando o afastamento da personalidade jurídica da empresa e alcançar os bens dos sócios. Vale ressaltar que esta teoria dispensa qualquer análise mais apurada e delicada para que seja realizada a desconsideração, basta apenas que a pessoa jurídica não possua bens suficientes em seu patrimônio que cubram o crédito perquirido, para que os sócios sejam responsabilizados pelas dívidas da sociedade.

A teoria maior da desconsideração da personalidade jurídica, contrária a teoria menor, permite uma avaliação mais profunda e eficaz, de uma maneira a exigir requisitos mais coesos para a identificação de uma fraude. Com tudo, fica mais do que claro que o exercício da desconsideração da personalidade jurídica é necessário a comprovação de uma efetiva demonstração de fraude ou abuso de direito por parte dos administradores ou sócios, mas levando em conta que a desconsideração é uma medida de caráter excepcional, sendo assim, não podendo ser usada de maneira indistinta (Costa, 2008).

Tal segurança é primordial para todo e qualquer empreendedor que deseja se lançar dentro do mercado, afinal, se toda pessoa que abrisse sua própria empresa/negócio estivesse sobre o risco iminente de seu patrimônio pessoal ser afetado, em decorrência do insucesso da atividade empresária, certamente haveria um fatal desestimulo ao empreendedorismo no nosso País. A desconsideração da personalidade jurídica é um dos riscos principais e um dos mais temidos em operações de investimento-anjo no Brasil. A desconsideração da autonomia patrimonial da pessoa jurídica ("desconsideração da personalidade jurídica") é medida extrema e cirúrgica, coibindo a fraude ou o abuso de direito e, de uma forma mais simples e objetiva, pois incluídos nos dois institutos citados, a confusão patrimonial, permitindo que no caso em concreto, respeitado o devido processo legal, o credor alcance os bens particulares dos sócios e administradores (Bushatsky, 2017).

A teoria da desconsideração da personalidade jurídica não é contrária à personalização das sociedades empresárias e à sua autonomia em relação aos sócios. Ao contrário, seu objetivo é preservar o instituto, coibindo práticas fraudulentas e abusivas que dele se utilizam (Coelho, 2012). Ela reforça a autonomia patrimonial da pessoa jurídica e a preservação da empresa, não devendo ser utilizada tão somente porque a pessoa jurídica não tenha mais bens para satisfazer aos seus credores. Existem diversas teorias a respeito da aplicação da desconsideração da personalidade jurídica, entretanto, com os termos "alto", "baixo" e "baixíssimo" foram designados como uma como forma de classificar o custo de manutenção de cada tipo societário com base nas exigências legais.

Ao analisar a desconsideração da personalidade jurídica, deve-se levar em consideração a existência ou não de culpa, o que faz gerar a existência de duas espécies: subjetiva ou objetiva. Espécie subjetiva: descreve a necessidade de se analisar a 
culpa dos sócios antes de ocorrer a desconsideração da personalidade jurídica; Espécie objetiva: basta a ocorrência de um determinado fato para ocorrer a desconsideração da personalidade jurídica, independentemente de análise de culpa.

Entretanto, com a amplitude dada pelo artigo 50 da Lei n. 10.406, de 10 de janeiro de 2002, do Código Civil, não são raros os casos em que isso acontece:

A desconsideração da personalidade jurídica tem sido conceituada como a suspensão temporária da personalidade jurídica, em determinado caso concreto, atribuindo-se aos seus sócios ou administradores as relações que inicialmente seriam imputadas à pessoa jurídica, isso é, sócio ou administradores, em determinadas situações, pode vir a ser pessoalmente responsáveis por dívidas da empresa [...] No Direito do Trabalho, nos últimos anos, a aplicação da teoria tem sido feita de forma ampla (Coelho; Garrido, 2016, p. 118).

O art. 50 do Código Civil fixou expressamente a necessidade de existência do abuso do direito para a declaração de desconsideração, e elegeu como circunstâncias caracterizadoras deste abuso o desvio de finalidade ou a confusão patrimonial. Contudo, a utilização do instituto é possível quando presentes os pressupostos previstos em lei, ou seja, devendo ser observado se o caso concreto é passível de desconsideração da personalidade jurídica, pois quando não estão presentes os pressupostos para desconsideração ou quando for possível a responsabilização direta do sócio administrador por ato praticado, não é cabível a desconsideração da personalidade jurídica. Ainda, do ponto de vista empresarial como trabalhista existe o risco de invasão do patrimônio do empreendedor e do investidor por serem sócios da empresa. Por esta razão, muitos investidores buscam instrumentos que permitam uma maior proteção em casos como esse. Normalmente, isso significa uma operação em que eles possam entrar como sócios apenas quando a sociedade estiver mais robusta, capitalizada e com menores riscos jurídicos, por já terem uma estrutura mais organizada.

Quanto à infração de lei expressa, violação dos estatutos e contrato social, deve haver responsabilização pessoal e direta do administrador, o agente precisa ser responsabilizado para reparar/indenizar os danos causados conforme previsto no Código Civil. Outra forma que o investidor utiliza para se precaver de riscos jurídicos como esse é fazendo a chamada (due diligence) ou auditoria. Isso permite uma avaliação das condições da empresa e de possíveis processos que estejam correndo assim como verificar práticas adotadas que possam representar riscos desnecessários (Spina, 2015).

A desconsideração da personalidade é uma forma eficaz de coibir fraudes e ainda assim preservar a pessoa jurídica, sendo elemento essencial no nosso ordenamento jurídico que merece constantes estudos para que haja cada vez mais a consciência de que a desconsideração da personalidade jurídica é uma forma eficaz de se coibir o abuso da pessoa jurídica, por ser um mecanismo no qual o patrimônio dos sócios é atingido para satisfazer os prejuízos decorrentes desses eventuais abusos.

\section{Considerações Finais}

A partir da pesquisa realizada foi possível concluir que apesar de empreendedores, investidores e advogados ainda encontrarem barreiras para concretização de projetos e investimentos, tanto do ponto de vista jurídico como econômico, existe uma predisposição destes atores em encontrar soluções para tais desafios.

Conforme analisado, a Lei Complementar no 155/2016 que traz consigo o "contrato de participação", ou que na forma usual seria entendido no meio empresarial como um entendimento entre as partes (memorando), que apesar de configurar como uma quebra de expectativas, a nova lei trouxe vantagens, como inserir na legislação brasileira uma definição para investimento-anjo, tentando regular a relação entre as partes deste tipo de investimento, visando trazer maior segurança jurídica para as operações.

Se os advogados que assessoram estas operações estiverem atentos às demandas jurídicas e não-jurídicas deste mercado, poderão criar alternativas para tornar estes projetos e investimentos possíveis. Principalmente no que se refere à 
natureza do investimento-anjo, a negociação possui um caráter pessoal. É unânime que precisa haver uma confiança profunda entre investidor e empreendedor, o investidor prefere excelentes empreendedores com más ideias do que excelentes ideias com maus empreendedores. Isso porque num mercado como o das startups, uma má ideia pode ser transformada e, eventualmente, dar certo nas mãos de alguém com competência e talento, ao contrário de uma boa ideia que jamais tenha sucesso se for mal executada.

A solução é mudar o enfoque do jogo ganha-perde, para o ganha-ganha, inserindo todos os idealizadores e investidores com um mesmo objetivo, o qual, somente será possível delimitar com regras claras, para as quais a redação e modelagem societárias são fundamentais. Ademais, é importante que se desenvolva um bom ecossistema empreendedor e, que dê condições favoráveis ao surgimento de startups inovadoras, e em vista disto, o Estado e o Direito desempenham papéis relevantes, uma vez que as relações jurídicas, sejam legais ou contratuais, influenciam, diretamente, o desempenho desses negócios e, consequentemente, impactam nos possíveis benefícios que eles trazem.

No final das contas, o mais importante para o sucesso deste mercado, em termos jurídicos, parece ser a forma que o Direito é utilizado e não a disponibilidade de novas alternativas. Isso não significa que não existem barreiras jurídicas para serem enfrentadas nem que o mercado não se beneficiaria de novas soluções. Significa que é possível garantir segurança jurídica utilizando os instrumentos existentes, sendo preciso desenvoltura e criatividade por partes dos advogados para adaptálos à realidade moderna das startups. Se não houvesse forma juridicamente viável e segura de realizar investimento-anjo no Brasil, este mercado não estaria crescendo nos dias atuais, como de fato está.

Por fim, percebe-se que a inovação proporcionada pelos modelos de negócios das startups são favoráveis a atuação do advogado, proporcionando inúmeras oportunidades na carreira jurídica, sejam elas na advocacia prática, como na assessoria jurídica, uma vez que o operador do direito torna-se uma fonte de conteúdo informativo ao empresário, o que facilita na tomada de decisões quanto aos rumos da empresa. Além disto, identifica-se no advogado a figura do facilitador de negociação, ao auxiliar o empreendedor a fazer o melhor negócio, seja através de conselhos pontuais, como mediante revisões contratuais, a fim de garantir a integridade da propriedade intelectual, ou até mesmo por meio do networking ao aproximar potenciais investidores à startup.

A partir do estudo realizado observa-se a pertinência da temática no ramo jurídico-empresarial, restando claro a necessidade de novas pesquisas no campo das startups, principalmente a fim de detalhar a evolução da legislação frente a paradigmas do direito empresarial, com vistas a proporcionar novas investigações e novos conhecimentos.

\section{Referências}

Abstartups. (2020). Associação brasileira de startups. https://abstartups.com.br/

Abvcap - Associação Brasileira de Private Equity e Venture Capital. (2015). Estrutura Legal dos fundos de Private Equity e Venture Capital no Brasil.

Agência IN. (2014). 25\% das startups brasileiras morrem em menos de um ano. https://www.investimentosenoticias.com.br/noticias/negocios/25-das-startupsbrasileiras-morrem-em-menos-de-um-ano.

Anjos do Brasil. (2020). Investidor Anjo - Guia de Investimento Anjo \& Documentos Legais. https://www.anjosdobrasil.net/guia.html

Associação Nacional de Pesquisa e Desenvolvimento das Empresas Inovadoras. (2019). Mapa do Sistema Brasileiro de Inovação, 15 de julho de 2019 in Cooperação para Inovação. http://anpei.org.br/a-importancia-do-sistema-nacional-de-inovacao-para-o-desenvolvimento.

Banco Nacional de Desenvolvimento Econômico e Social. (2020). BNDES Garagem - Apoio ao Desenvolvimento de Startups. https://www.bndes.gov.br/wps/portal/site/home/onde-atuamos/inovacao/bndes-garagem.

Brasil. (2002). Lei $n^{o}$ 10.406, de 10 de janeiro de 2002. Institui o Código Civil. http://www2.camara.leg.br/legin/fed/lei/2002/lei-10406-10-janeiro-2002432893-publicacaooriginal.

Brasil. (2016). Instrução 578 da Comissão de Valores Mobiliários, de 30 de agosto de 2016. Dispõe sobre a constituição, o funcionamento e a administração dos Fundos de Investimento em Participações. http://conteudo.cvm.gov.br/export/sites/cvm/legislacao/instrucoes/anexos/500/inst578consolid.pdf. 
Research, Society and Development, v. 10, n. 6, e38510615871, 2021

(CC BY 4.0) | ISSN 2525-3409 | DOI: http://dx.doi.org/10.33448/rsd-v10i6.15871

Bushatsky, D. B. (2017). Desconsideração da personalidade jurídica. Enciclopédia jurídica da PUC-SP. Celso Fernandes Campilongo, Alvaro de Azevedo Gonzaga e André Luiz Freire (coords.). Tomo: Direito Comercial. Fábio Ulhoa Coelho, Marcus Elidius Michelli de Almeida (coord. de tomo). Pontifícia Universidade Católica de São Paulo.

Campos, N. M. (2015). The myth of the idea: and the upsidedown startup. Charleston: Createspace.

Coelho, G. T.; \& Garrido, L. G. (2016). Dissecando o contrato entre startups e investidores anjo. In: JÚDICE, Lucas Pimenta. NYBO, Erik Fontenele (Org.) Direito das Startups. Juruá, 115.

Coelho, F. U. (2014). Curso de Direito Empresarial - Direito de empresa. (2). Saraiva.

Cohen, S. (2013). What do accelerators do? insights from incubators and angels. Innovations, 8(3).

Costa, M. S. Q. P. (2008). A desconsideração da personalidade jurídica posterior à penhora on-line. Revista Jus Navigandi, 13(1710).

Cumming, D.; \& Johan, S.A. (2009). Venture Capital and Private Equity Contracting: an International Perspective. Burlington: Elsevier.

Distrito. (2020). Plataforma de Inovação para Grandes Empresas. https://distrito.me/

Galvão, H. (2018). Advogados, startups e o "Vale da Morte". https://www.linkedin.com/pulse/advogados-startups-e-o-vale-da-morte-helder-galvão/.

Garrido, L. G.; \& Coelho, G. T. (2016). A estruturação do investimento entre aceleradoras e startups no Brasil. In: Júdice, L. P., Nybo, E. F. (Orgs.). Direito das Startups. Juruá, 131.

Inova RS. (2020). Secretaria de Inovação, Ciência e Tecnologia do Estado do Rio Grande do Sul. https://www.inova.rs.gov.br/programa-inovars.

Lopes, R. K. (2018). A possibilidade de instauração ex officio do Incidente de Desconsideração da Personalidade Jurídica previsto no novo Código de Processo Civil. https://www.rkladvocacia.com/possibilidade-de-instauracao-ex-officio-do-incidente-de-desconsideracao-da-personalidade-juridica-previstono-novo-codigo-de-processo-civil-2/\#_ftn1.

Mason, C.; \& Brown. R. (2014). Entrepreneurial Ecosystems and Growth Oriented Entrepreneurship. https://www.oecd.org/cfe/leed/Entrepreneurialecosystems.pdf.

Minayo, M.C.S. (1983). Quantitativo-Qualitativo: oposição ou complementaridade. Cadernos de Saúde Pública. 9(3), 239-262.

Moraes, R.; \& Galiazzi, M. C. (2016). Análise Textual Discursiva: Processo Reconstrutivo de Múltiplas Faces. Ciência \& Educação, 12(1), 117-128.

Popper, K. S. (1975). A lógica da pesquisa científica. (2a ed.) Cultrix.

Reeves, M.; Moose, S.; \& Venema, T. (2010). BCG Classics Revisited: The Growth Share Matrix. https://www.bcgperspective.com/comtent/articles/c orporate_strategy_portfolio_management_strategic_planning_growt_share_matrix_bcg_classics_revisited/.

Rodriguez, J. A. H. (2015). Start-up Development in Latin America: The Role of Venture Accelerators.

Seghers, M. S.; \& Vanacker, T. (2012). The Impacto of Human and Social Capital on Entrepreneurs'Knowledge of Finance Alternatives. Journal of Business Management. Washingon, 1(50), 63-86.

Spina, C. A. (2012). Como encontrar e abordar um investidor-anjo? In: Grando, N. (Org.). Empreendedorismo Inovador: Como criar startups de tecnologia no Brasil. Évora, 411-426.

Spina, C. A. (2015). Investidor anjo: como conseguir investidores para seu negócio. (2a ed.) nVersos.

Startse. (2018). 7 startups do mundo jurídico que estão mudando o direito no Brasil. https://www.startse.com/noticia/startups/7-startups-do-mundo-juridicoque-estao-mudando-o-direito-no-brasil.

Start-up Brasil. (2018). Programa Nacional de Aceleração de Startups. O Direito na vida das Startups. https://www.startupbrasil.org.br/2018/08/30/o-direitona-vida-das-startups.

Zuini, P. (2013). Por que sua startup precisa de assessoria jurídica: O ideal é que uma startup tenha assessoria jurídica desde o seu início. https://exame.com/pme/por-que-sua-startup-precisa-de-assessoria-juridica/. 